\title{
Approach to Harmonic Mitigation Study in Wind Turbine Energy Conversion Systems Using Three Phase Boost Rectifiers
}

\author{
M. A. Hossain ${ }^{1}$, N. Afrin ${ }^{2}$, M. Feroz $\mathrm{Ali}^{2}$ \\ ${ }^{1}$ Department of Electrical and Electronic Engineering, Jessore University of Science and Technology, Jessore - \\ 7408, Bangladesh \\ ${ }^{2}$ Dept Department of Electrical and Electronic Engineering, Pubna University of Science and Technology, \\ Pabna, Bangladesh
}

\begin{abstract}
Wind energy is an important source of electrical power in recent years. $d$ summarize the content of the paper. Its main advantage comes from the fact of being a renewable and environmental-friendly energy. Permanent magnet synchronous generators (PMSG) applied to wind energy conversion system (WECS) using variable speed operation is being used more frequently in wind turbine application. Variable speed systems have several advantages over the traditional method of operating wind turbines, such as the reduction of mechanical stress and an increase in energy capture. To allow the variable speed operation of the PMSG WECS a conventional three-phase bridge rectifier (BR) with a bulky capacitor associated with a voltage source current controlled inverter (VS-CCI) is used. This paper presents a comparative simulation study between three different approaches applied to harmonic mitigation in PMSG WECS. The studied techniques are single-switch three-phase boost rectifier and three-phase boost type PWM rectifier.
\end{abstract}

Keywords: Harmonic mitigation, PMSG, WECS, Bridge rectifier, Boost rectifier.

\section{INTRODUCTION}

Now a day's worldwide energy crisis is one of the great problem. The interest in renewable energy has been revived over last few years, especially after global awareness regarding the ill effects of fossil fuel burning. The use of renewable energy technology to meet the energy demands has been steadily increasing for the past few years, however, the important drawbacks associated with renewable energy systems are their inability to guarantee reliability and their lean nature. Renewable energy sources are considered to be the better option to meet these challenges. The amount of energy captured from a WECS depends not only of the wind at the site, but depends of the control strategy used for the WECS and also of the conversion efficiency. Permanent magnet synchronous generators (PMSG) on wind energy conversion system (WECS) with variable speed operation are being used more frequently in low power wind turbine application. Variable speed systems have several advantages such as the reduction of mechanical stress and an increase in energy capture. In order to achieve optimum wind energy extraction at low power fixed pitch WECS, the wind turbine generator (WTG) is operating in variable-speed variable-frequency mode. The rotor speed is allowed to vary with the wind speed, by maintaining the tip speed ratio to the value that maximizes aerodynamic efficiency. The PMSG load line should be matched very closely to the maximum power line of the WTG. MPPT control is very important for the practical WECS systems to maintain efficient power generating conditions irrespective of the deviation in the wind speed conditions. To achieve optimal power output, a sensor-less scheme including a wind turbine model was developed by Tan et al in [1]. The developed wind turbine model will be used in this work in order to evaluate the different harmonic mitigation approaches. Instead of all this complex control theory to get MPPT on PMSG WECS, the standard way to implement a grid connected PMSG WECS with variable speed is using two conversion stages: the first one an AC-DC stage and the second one a DC-AC stage. To build the first one a classical three phase bridge rectifier (BR) associated to a bulky capacitor is used and the second stage may be implemented by two types of converters schemes Voltage source current controlled inverter (VS-CCI) and Line commutated inverter (LCI) as shown in Fig. 1. This paper has the main focus in the first energy conversion stage the AC-DC converter, which is responsible by an injection of a high harmonic current content into the PMSG. These currents circulating into the machine will generate losses. This work applies three well-known approaches to harmonic mitigation in three-phase AC-DC converters to WECS [2, 3 and 4]: a) harmonic trap filters (HTF), b) single-switch three-phase boost rectifier (PFC) and c) a three-phase boost type PWM rectifier ( $\mathrm{PWM}_{\mathrm{REC}}$ ). Using these approaches is possible to minimize the current harmonic content.

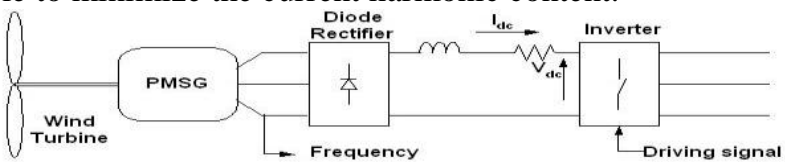

Figure 1. Wind Energy Conversion System. 
A software simulation model developed in using PSIM ${ }^{\circledR}$ software, which allows easy performance evaluations, is used to estimate the behavior of these three different schemes associated with the PMSG WECS. Simulation results showed the possibility of achieving maximum power tracking, output voltage regulation and harmonic mitigation simultaneously.

\section{WIND TURBINE MODEL}

The In a wind turbine system, the kinetic energy in the wind is converted into rotational energy in a rotor of the wind turbine. The rotational energy is then transferred to a generator, either directly or through a gearbox for stepping up the rotor speed. The mechanical energy is then converted to electrical energy (variablefrequency, variable-voltage) by the generator. From the generator, the electrical energy is transmitted to a utility grid either directly or through an electrical energy conversion stage that produces constant-frequency, constantamplitude voltage suitable for interface to the utility. The WECS considered in this work consists of a PMSG driven by a fixed pitch wind turbine; an AC-DC energy conversion stage implemented using three different approaches and a VS-CCI. The entire system is shown in Fig. 1. A brief description of each element of the system is given below. The output power of the wind turbine is given by the equation. $P_{m}=\frac{1}{2} C_{p}(\beta, \lambda) \rho A V^{3}$

The $\mathrm{C}_{\mathrm{p}}$ curve for the wind turbine used in this study is shown in Fig. 2. The wind turbine output mechanical torque is affected by the $\mathrm{C}_{\mathrm{p}}$.

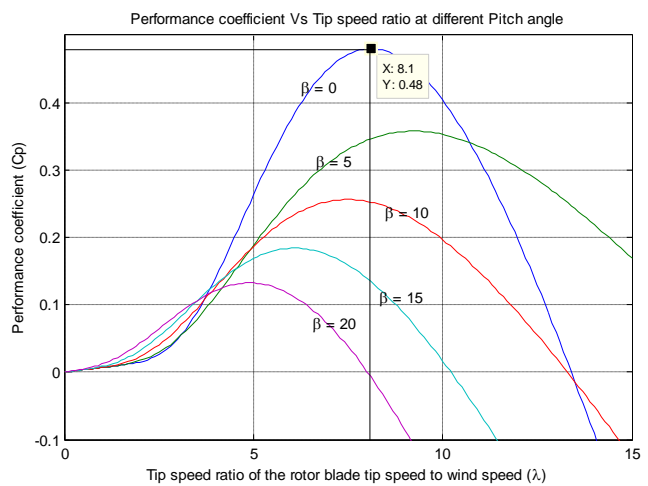

Figure 2. Power coefficient vs. Tip speed ratio with $\beta=0,5,10,15,20$ degree

From the $\mathrm{C}_{\mathrm{p}}-\lambda$ characteristics, for different values of the pitch angle $\beta$, are illustrated above. The maximum value of $\mathrm{Cp}\left(\mathrm{C}_{\mathrm{p} \text { max }}=0.48\right)$ is achieved for $\beta=0$ degree and for $\lambda=8.1$. It has the maximum value of 0.59 . The maximum power is extracted from the wind at that speed ratio. The theoretical maximum value of $\mathrm{Cp}$ is 0.59 . In practical designs, the maximum achievable $\mathrm{Cp}$ is below 0.5 for high-speed, two-blade turbines, and between 0.2 and 0.4 for slow speed turbines with more blades. The wind turbine output mechanical torque is affected by the $\mathrm{C}_{\mathrm{p}}$. In order to maximize the aerodynamic efficiency, the $\mathrm{T}_{\mathrm{e}}$ of the PMSG is controlled to match with the wind turbine $\mathrm{T}_{\mathrm{m}}$ to have maximum possible $\mathrm{C}_{\mathrm{pmax}}$. With a power converter, adjusting the electrical power from the PMSG the $T_{e}$ may be controlled, therefore the rotor speed can be controlled. To operate at maximum power at all wind speeds, the electrical power output from the power converter controller must be continuously changed compensating wind speed variation conditions to have the system always matched on the maximum power locus. The complete grid connected sensor-less PMSG WECS scheme using a well-known three-phase six-pulse bridge rectifier and two bulky capacitors are shown in Fig. 3.

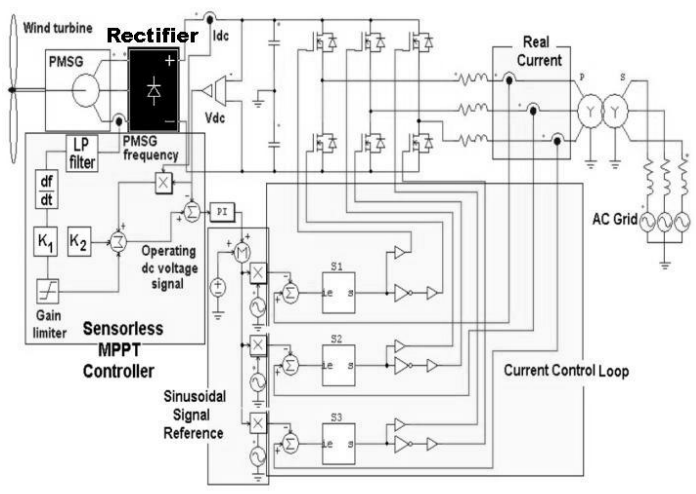

Figure 3. Implemented sensor-less VS-CCI WECS. 


\section{HARMONIC ANALYSIS BY BOOSTER RECTIFER}

Winds are caused by the uneven heating of the atmosphere by the sun, the irregularities of the earth's surface, and rotation of the earth. Wind is a renewable resource because it is inexhaustible. It is a result of the sun shining unevenly on the earth. Since wind turbine output is proportional to the cube of the wind speed, the wind turbine generator output fluctuates due to wind speed variations. The loading characteristic of the PMSG WECS can be easily simulated by connecting an adjustable load resistor to the PMSG and rectifier terminal. In order to extract the peak power from the WTG at a given wind speed, the WECS has to match closely to the maximum power curve. One of the possible power factor correctors (PFC) approaches, suitable to implement the input rectifier, the black block shown in Fig. 3, was the three-phase DCM boost rectifier proposed by Prasad and Ziogas [3]. The control of the DC power output is easily made by duty cycle control. Only a single active device such as a MOSFET or IGBT is needed. The main disadvantages of this implementation are the increasing of the power losses in the devices comparing with the conventional three-phase ACDC converter and the necessity of an additional input filter to remove the high-frequency harmonic components of the input currents [3,4]. Therefore, the implementation of the input rectifier using a single-switch three-phase boost rectifier will result in harmonic mitigation on the PMSG output currents. The complete schematic diagram of the three-phase DCM boost rectifier is shown in Fig. 4. Inductors $L 1, L 2$, and $L 3$ have the same small value, such as they operate in the discontinuous conduction mode in conjunction with diodes $\mathrm{D}_{1}-\mathrm{D}_{6}$. At the end of the transistor $Q_{1}$ conduction subinterval, the inductor currents reach peak values, which are also proportional to the applied three-phase line-to-neutral voltages. When transistor $Q_{1}$ turns off, then diode $D_{7}$ becomes forward-biased and the inductors discharge their stored energies to the DC output. Since the peak input currents are proportional to the applied input line-to-neutral voltages, then the average values of the input currents are also approximately proportional to the input line-to-neutral voltages [4].

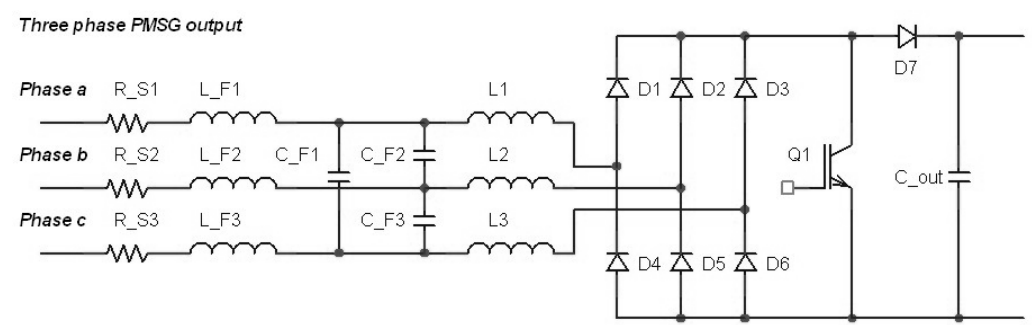

Figure 4. Single-switch three-phase boost rectifier.

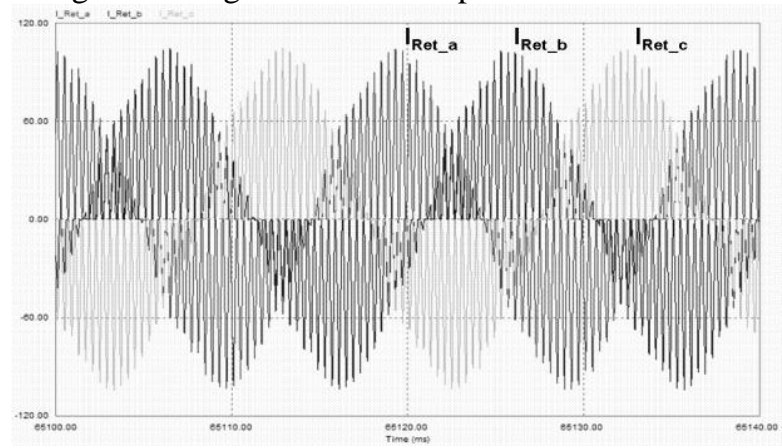

Figure 5. Three-phase bridge rectifier input currents.

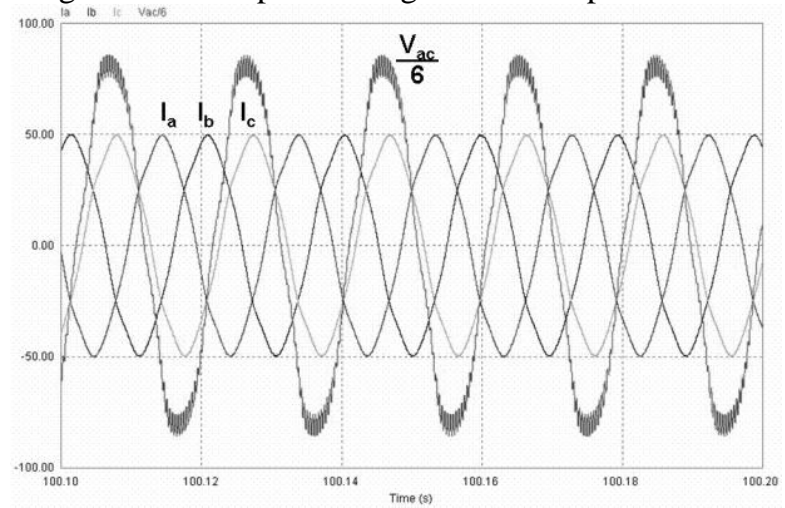

Figure 6. Three-phase PMSG output currents and line-to-line voltage divided by 6 using 3-Phas Boost Rectifier. 


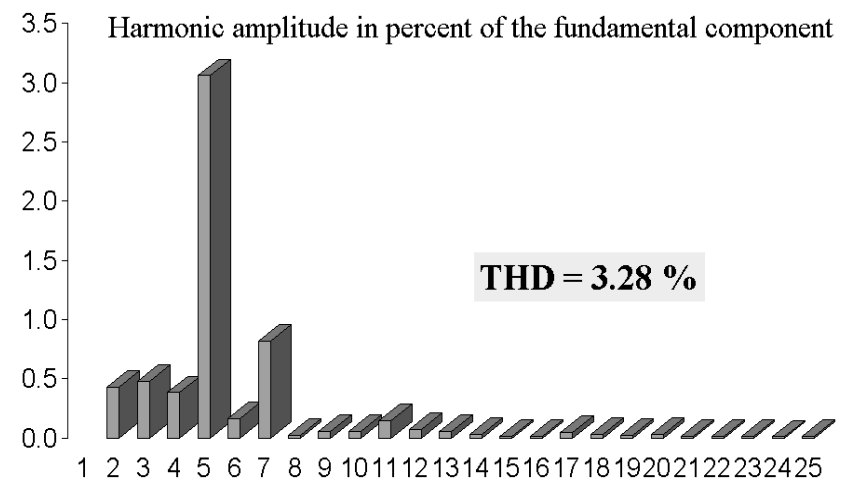

Figure 7. Harmonic content of the PMSG current output using Three-Phase Boost Rectifier.

The three-phase PMSG output currents and also the line-to-line voltage (divided by 6) are represented in Figure 6. The PMSG output current harmonic content is shown in figure 7.

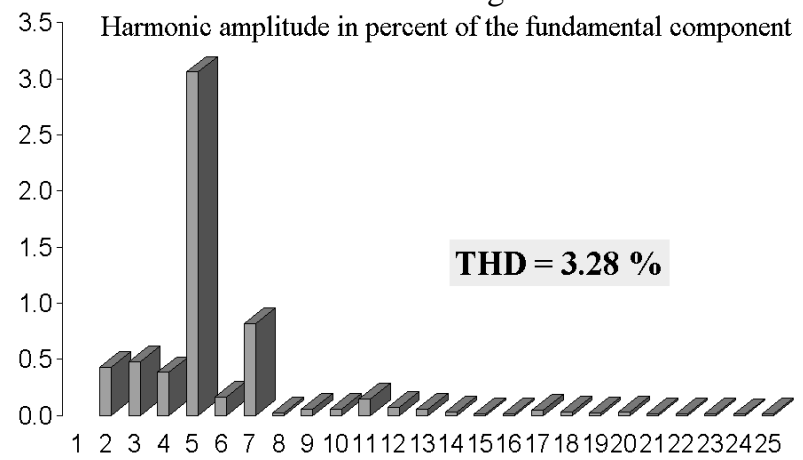

Figure 8. Harmonic content of the PMSG current output using Three-Phase Boost Rectifier

\section{HARMONIC ANALYSIS BY BOOST TYPE PWM RECTIFIER}

As it was mentioned before, the behaviour of the Three-Phase Boost type PWM Rectifier $\left(\mathrm{PWM}_{\mathrm{REC}}\right)$ associated to PMSG WECS is studied in this work focused in losses reduction on PMSG by harmonic mitigation. The three-phase boost type PWM rectifier has the capability of working as an ideal PFC, with very low THD at any operation point. Hence, it will be investigated in this work. The inductors and capacitor filter the high-frequency switching harmonics, and have little influence on the low frequency AC components of the waveforms. The three-phase boost type PWM rectifier shown in Fig. 9. The three-phase bridge rectifier input currents are shown in figure 10. From this figure, it is easy to observe the CCM and the very good results obtained. The PMSG output current harmonic content is shown in figure 11.

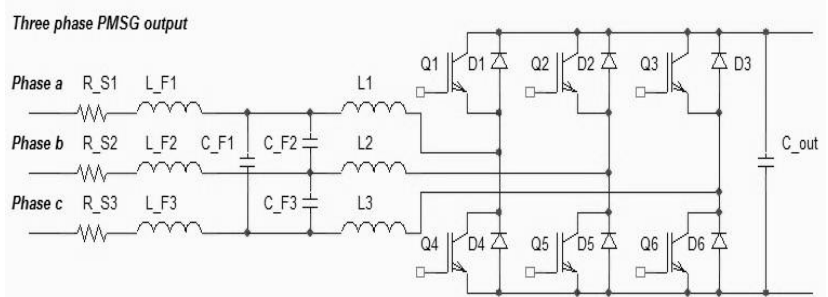

Figure 9. Three-phase boost type PWM rectifier.

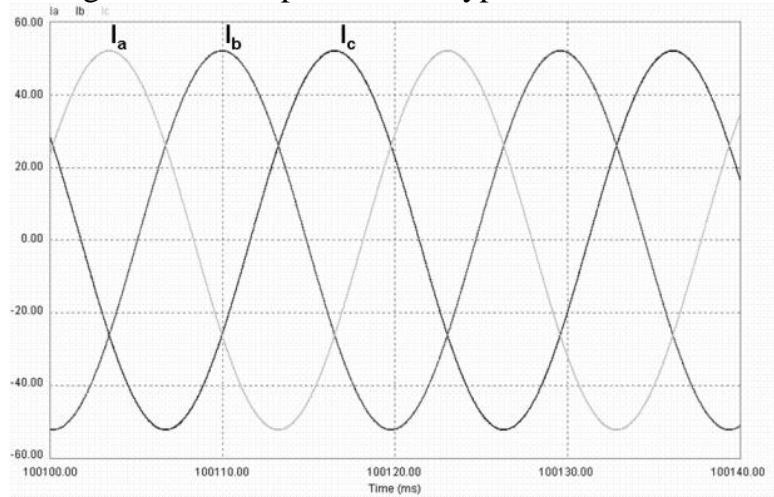

Figure 10. Three-phase bridge rectifier input currents. 


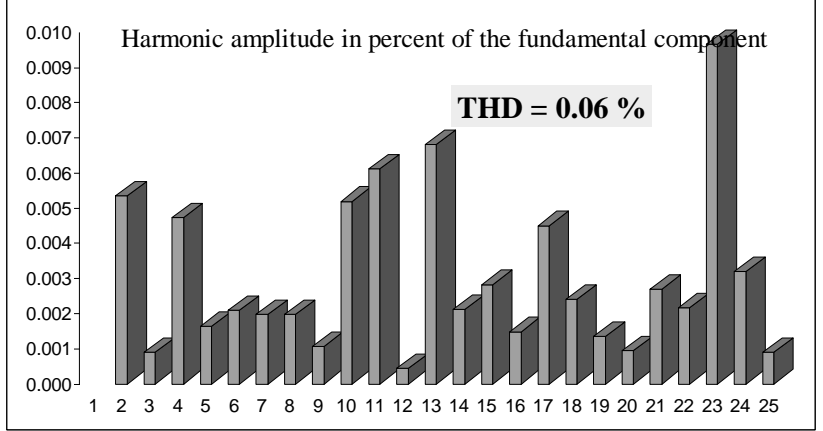

Figure 11. Harmonic content of the PMSG output current using Three-Phase Boost Rectifier.

\section{CONCLUSION}

A In this paper, three well-known harmonic mitigation solutions were applied to PMSG WECS AC to DC conversion using single-switch three-phase boost rectifier (PFC) and a three-phase boost type PWM rectifier. It is also important to remark that to use HTF results in bulky components. For all these reasons, it is not a recommended way out to obtain harmonic mitigation on PMSG WECS. On the other hand, the singleswitch three-phase boost rectifier has presented encouraged results. Such as: low current and voltage THD, simple power topology and control circuit, can work in all wind conditions and presents a real reduction of the PMSG total losses, which allows to expect lifetime increasing in the PMSG without power capability reduction.

K. Tan and S. Islam, "Optimum Control Strategies in Energy Conversion of PMSG Wind Turbine System Without Mechanical Sensors", IEEE Transactions on Energy Conversion, Vol. 19, No. 2, June 2004, pp. 392-400.

[2] Phipps, J.K.;"A transfer function approach to harmonic filter design", Industry Applications Magazine, IEEE, Volume: 3 , Issue: 2 , March-April 1997, pp.:68-82.

[3] A. R. Prasad, P. D. Ziogas, and S. Manias, "An active power factor correction technique for three-phase diode rectifiers," in PESC'89 Rec., pp. 58-65.

[4] Robert W. Erickson, "Some Topologies of High Quality Rectifiers" Keynote paper, First International Conference on Energy, Power, and Motion Control, May 5-6, 1997, Tel Aviv, Israel, pp. 1-6.

[5] Kaboli, Sh.; Zolghadri, M.R.; Homaifar, A., "Effects of sampling time on the performance of direct torque controlled induction motor drive", IEEE International Symposium on Industrial Electronics, 2003. ISIE '03, Volume: 2 , June 9-11, 2003, pp.:1049 1052

[6] Yao Tze Tat, "Analysis of Losses in a 20kW Permanent Magnet Wind Energy Conversion System", in the Department of Electrical and Computer Engineering. Western Australia: Curtin University of Technology, October 2003. pp. 101.

\section{BIOGRAPHY}

M. Amzad Hossain is pursuing MSc Engg degree in department of electrical and electronic Engineering in Rajshahi University of Engineering \& Technology, Rajshahi Bangladesh in 2010. Presently he is working in department of Electrical and Electronic Engineering in Jessore University of Science and Technology, Bangladesh, Mr. Hossain is actively involved in study, research, teaching and consulting project works with undergraduate students. His research interests in renewable energy and power system stability.

N. Afrin has obtained his BSc Engg degree in Electrical and Electronic Engineering from Rajshahi University of Engineering \& Technology, Bangladesh in 2012. Presently she is working in department of electrical and Electronic Engineering in Pabna University of Science and Technology, Pabna, Bangladesh. Her research interests in renewable energy and optical communication.

M. Feroz Ali has obtained his BSc Engg degree in Electrical and Electronic Engineering from Rajshahi University of Engineering \& Technology, Bangladesh in 2012. Presently he is working in department of Electrical and Electronic Engineering in Pabna University of Science and Technology, Pabna, Bangladesh. His research are Renewable energy and Microwave field and waves. 